\title{
Current Status of Remoting Sensing Application
}

\author{
Xiao Chen*
}

STEM

University of South Australia

Adelaide, Australia

chexy135@mymail.unisa.edu.au

\begin{abstract}
Remote sensing is a technique for identifying the Earth's environment and resources by gathering electromagnetic radiation data from man-made satellites, planes, and other aircraft. This makes up for the shortcomings of manual monitoring which is limited by ground conditions and small monitoring range. This paper reviews some basic technical applications of remote sensing and two major Earth observation programs that have been used in recent decades. In addition, this article also discusses the application of remote sensing in urban planning and development, plant monitoring and disaster prediction. Most of these aspects are the main application aspects of remote sensing and have a very important impact on the development of human society. Some technical and analytical deficiencies have also been discussed. Some future prospects have been raised accordingly based on these restrictions as well. These applications reflect some practical problems, and can benefit urban, agricultural, and earthquake observations to a large extent by providing new data or methods.
\end{abstract}

Keywords-Remote sensing, Urban planning, Forecast of disasters

\section{INTRODUCTION}

In recent years, with the rapid population growth and economic development, the trend of urbanization has become more and more obvious. This has had a certain impact on the natural environment of the city. The impact of artificial impervious area and heat island effect on cities is also increasing. This urgently requires people to carry out a sustainable development plan. This requires government and other departments to monitor some key data. Remote sensing can help people detect objects on the earth from a distance. It is a data collection method with the advantages of high speed, low cost, and wide detection range [1].

Besides, food is the most fundamental condition for people to survive. Whether it can be supplied in sufficient quantity has a bearing on people's living environment. According to the United Nations (UN) World Food Programme, as of 2020, 155 million people will be in serious food insecurity. Remote sensing could provide important reference data for solving the problem of cultivated land in the food problem. Researchers can obtain land use distribution information from remoting sensing satellite. In addition, some geological activities, such as earthquakes, sometimes cause huge personal injury and property damage. Remote sensing technology can predict and monitor the extent of damage after the disaster.

With people's in-depth research, it is widely used in a few aspects of people's lives. In this article, it will introduce the development status and future expectations of remote sensing technology. First, it will introduce some basic knowledge of remote sensing technology, including the spectrum that is important for imaging and the satellites used for observation. The second part will discuss its specific applications in urban planning development, plant monitoring and forecast of disasters. Finally, combined with the literature review conducted above, prospects of remoting sensing application are proposed. 


\section{REMOTING SENSING TECHNOLOGY}

\subsection{Remoting sensing}

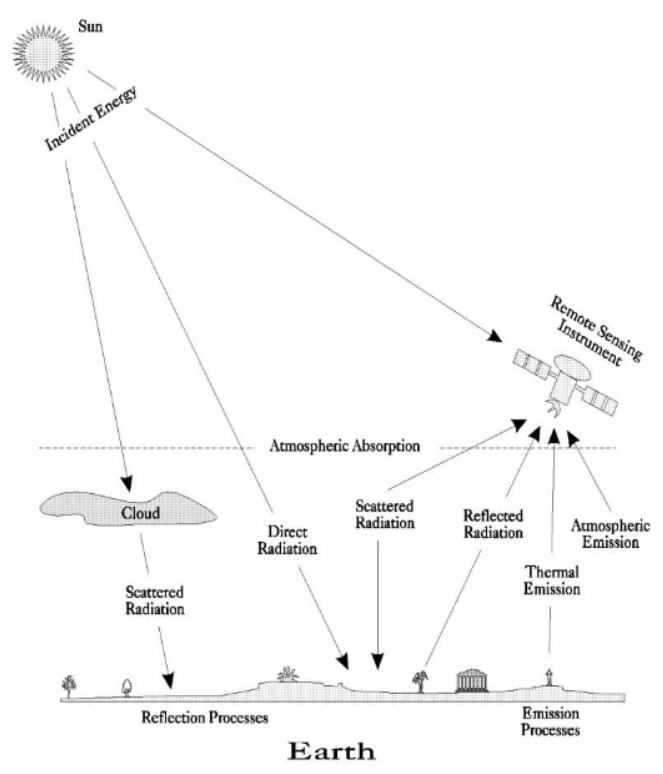

Figure 1. Remote sensing radiation system [2]

Remote sensing is the practice of detecting and monitoring an area's physical features by measuring the radiation reflected and emitted from a distance, usually from a satellite or airplane. Electromagnetic Radiation (EMR) is the basic data monitored by remote sensing. It is divided into two energy sources. One is natural EMR including the Sun's reflected light (source 1) and the Earth's emitted heat (source 2). The second type is Artificial, including microwave RADAR and LIDAR (source 3). When shortwave radiation strikes the Earth's surface, three types of interactions occur: absorption, transmission, and reflection. Their proportions are determined by the wavelength of the energy as well as the material and state of the feature [3]. These EMRs are scattered and refracted through the atmosphere and transmitted to objects and detectors. There is a ground segment on the ground. Space segment, for example, sensors 1, 2, and 3 carried by satellite will record and transmit corresponding energy sources $1,2,3$. Besides, atmosphere and clouds will also absorb, scatter and reflect EMR. Figure 1 graphically depicts the generalized processes involved in electromagnetic remote sensing of earth resources.

\subsection{Electromagnetic spectrum}

Electromagnetic waves are composed of photons and travel at the speed of light. People arrange these electromagnetic waves in the order of their wavelength or frequency, wave number, and energy, and their wavelength ranges from meters to nanometers. Various objects on the planet's surface exhibit different characteristics at different frequencies or wavelengths of the electromagnetic spectrum. Electromagnetic radiation includes X-rays, microwaves, radio waves, ultraviolet, infrared, and visible light. The wavelengths of various radiations are shown in Figure 2. The wavelength of the radio waves region is as high as $10^{\wedge} 6$. In contrast, the shortest wavelength appears in the gamma-ray range of $10^{\wedge}-18$. There are different spectra in such a large range, and visible light only accounts for a small part of it. The wavelength is only $0.4 \mathrm{~m}$ to $0.7 \mathrm{~m}$.

\section{The electromagnetic spectrum}

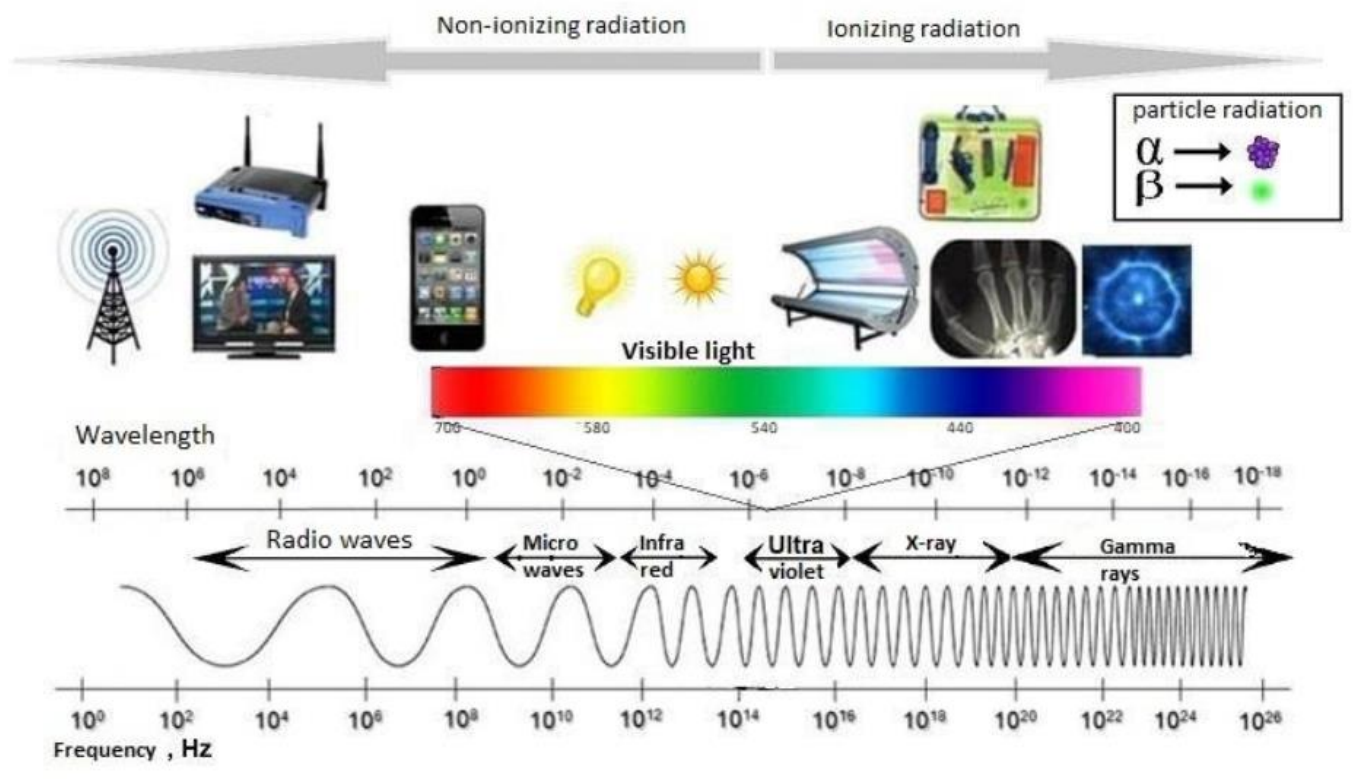

Figure 2. Overview of all electromagnetic radiation [4] 


\subsection{Earth observation programs}

Various types of earth observation satellites, space stations, deep space probes, and other artificial equipment have been successfully launched into international space since the $1960 \mathrm{~s}$, and a number of satellite earth observation programs have been implemented [5]. Climate change, resource and environmental change detection, and disaster risk reduction and prevention have all benefited from the use of aviation and aerospace earth observation applications. Satellite observation technology allows humans to obtain high-precision, high-time-resolution data of the atmosphere, ocean, and land. It can provide direct observation data and information for earth science research due to its global coverage of remote sensing data.

The origin of the research on Earth observation satellites is traced back to 1967. Two satellites, ERTS-A and ERTS-B, were named Earth Resources Technology Satellites [6]. In the following two years, with the development of a multispectral scanner, Hughes contracted with NASA. The first and only satellite dedicated to monitoring and studying the Earth, ERTSA, was launched on July 23, 1972, from an Air Force base in California. In 1975, NASA renamed this satellite Landsat 1, and the subsequent launch of ERTS-B was renamed Landsat 2. In the following decades, NASA launched eight more satellites, and Figure 3 shows when each of them was launched. Along with the development of sensor technology, the number of bands that can be observed has grown from the initial 4 from Landsat 1-3 to 11 from Landsat 8-9. In the latest satellites, the Operational Land Imager (OLI) and Thermal Infrared Sensor (TIRS) provide conditions for the detection of cirrus clouds, coastal and aerosol, et al.

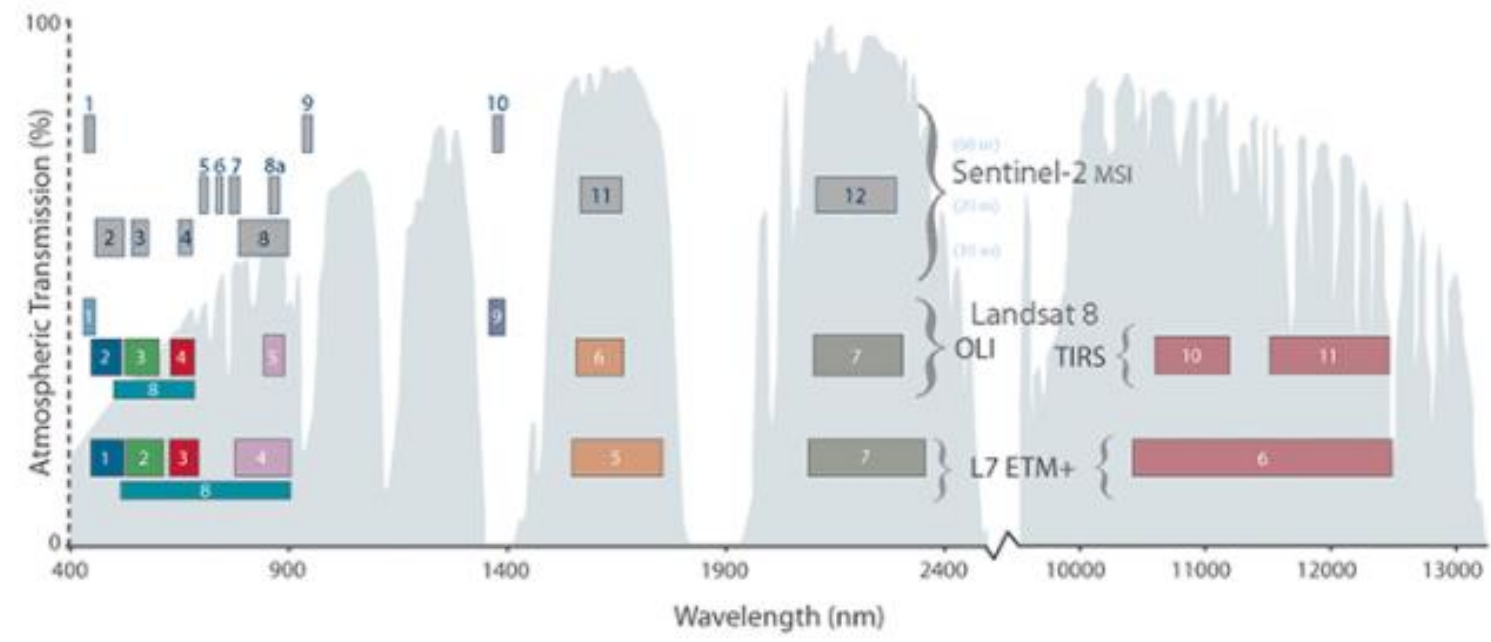

Figure 3. Comparison of Landsat 7 and 8 bands with Sentinel-2

\section{Remoting Sensing ApPlication}

With the help of remote sensing techniques and Earth observation programs described above, scholars can carry out research work in multiple fields. Satellites can investigate, monitor, analyze, predict and forecast resources, environment, disasters, regions, cities, etc. by remote observation and collecting relevant data. Remote sensing provides information that is more objective and accurate than traditional approaches. It can display the distribution of things on the ground surface in great detail. Remote sensing can provide information in different wavelengths such as visible and infrared light, as well as image and data-based information. Twodimensional, three-dimensional spatial information and the diverse information increase the aspect and depth of research.

\subsection{Urban planning development}

The world is experiencing urban growth again and is putting up with the acceleration of urbanization. A large number of inhabitants are gathered in cities. Almost half of the Earth's population lives in urban areas. Cities have a large population and a complex traffic situation. Cities are also a complex system of various interacting parts in time and space [7]. These all influence to some extent the spatial distribution of cities and the way soils are used. And with the global warming process, the changing face of the city also affects the urban climate as heat island effect.

3.1.1 Urban heat island effect: Urban heat island (UHI) is a phenomenon where the temperature of a city is higher than the surrounding countryside. The causes of this phenomenon are mentioned. The structure of the city makes the buildings absorb more solar radiation, because most of the buildings in the city have high 
density and low albedo coefficient. [8]. And the planning of the city has a great influence on the heat island effect.

The densification of the city, which is also widely adopted by urban planning this and stakeholders, may exacerbate the UHI [9]. This is due to the fact that compact cities have more buildings, possess a smaller specific heat capacity and have a greater heat absorption rate. Also, studies have shown that the greening of the city's landscape has significant results in reducing UHI. And the vegetation density and concentration status affect this efficiency [10]. Besides, weather is also an important influence factor. If more measures are taken to improve the urban layout, the UHI phenomenon can be improved, especially in community design and design of new development plots. In developed neighborhoods, increase the tightness of vegetation cover, as described above.

Several researchers are also developing computational simulation methods and projects to reduce this phenomenon. In terms of computational simulation, urban canopy models (UCM) and computational fluid dynamics (CFD) are used. However, due to the high complexity of cities and the implementation of boundary conditions that cannot be shown accurately and clearly, multi-scale models were brought up [11]. At the same time, this requires researchers to adapt both to be compatible. Santamouris [12] studied the development of highly reflective pavements. The principle is to use reflective coatings to increase the albedo of the pavement. At the same time there was a significant reduction in the surface temperature of the material on which the road was laid. This requires the researcher to adapt both of them for compatibility. Similarly, increasing the albedo of building façade materials is one way to do this. Green infrastructure, such as green roofs and green walls, can help to cool cities, especially in the summer. [13]. Although it has many advantages, considering the cost and the actual CO2 emissions [14]. More precise numerical modeling of UHI effects would be possible with more extensive measurements of soil and plant albedo values.

\subsubsection{Impervious surface area: Impervious surface} area (ISA) is the impermeable surface of a landscape that is created by human intervention, such as buildings, driveways, paved streets, parking lots, etc. The main cause of an increase in ISA is an increase in the amount and flow of runoff. This may lead not only to water and soil runoff, but also to an increase of harmful substances in the water bodies. And the biggest challenge in the observation is to cope with the hyperspectral diversity and mixed components registered at the pixel scale [15]. Dark, basal, green vegetation $(\mathrm{GV})$ and nonphotosynthetic vegetation (NPV) can demonstrate the spectral variability of a place.
When observing urban vegetation changes in China, the study found that urbanization and vegetation degradation in the 2010 s were largely influenced by anthropogenic impacts [16]. However, this did not occur close to the newly urbanized areas and the Qinghai-Tibet Plateau. This proves that ecological restoration efforts in newly urbanized areas are feasible. For the impervious surfaces in Beijing, the analysis concluded that the main drivers that may lead to changes in impervious surfaces are economic, and government regulations [17]. This illustrates the environmental protection measures and economic environment introduced by the government as possible ways to enhance the environment. Compared to Beijing, Yunnan Province has a significantly lower urbanization rate than other regions, but at the same time it proves that urbanization policies can change urban development. And the ISA extraction method is verified to be more accurate [18].

\subsection{Plant monitoring}

Insist on ecological environmental protection and enhance the sustainable development of the economy is the direction that most countries have been striving for. As an important part of environmental protection work, vegetation ecological monitoring has received more and more attention from people. Agriculture is the source of human food and clothing, the foundation of survival, and the primary condition of all production. If agriculture cannot provide food and necessary food, then people's lives will not be stable, production will not develop, and the country will lose its foundation of selfreliance. In addition, forests can absorb large amounts of carbon dioxide emitted by industrial combustion and urban residents' breathing, while releasing large amounts of oxygen to maintain a constant air composition. Its ecological and social benefits far exceed its own economic benefits. Therefore, forests need to be protected even more. Utilizing the difference in reflectance of green vegetation in the visible and nearinfrared bands, the reflectance of chlorophyll in the near-infrared band is significantly increased and determines the chlorophyll content, which can monitor the growth of vegetation. It is usually expressed as $\mathrm{NDVI}=(\mathrm{Ch} 2-\mathrm{CH} 1) /(\mathrm{Ch} 2+\mathrm{Ch} 1)$.

\subsubsection{Agriculture monitoring: Agriculture has been} the basic position of the national economy from ancient times to the present. Food and clothing are the basic pursuit of people's livelihoods. The necessity to boost food production to feed a growing population is one of the world's major issues in the future. To supplement their food supply, many of these individuals will have to rely on protected agriculture. During COVID-19, agriculture played an important role in the overall economy [19]. 
Greenhouses have been of great interest as one of the important components of agriculture. A study explored the spatial and temporal dynamics of greenhouses in the Shouguang region of northern China and concluded that greenhouses were expanding year by year as a result during the period 1990-2018. In addition, the distribution characteristics of greenhouses are fragmented, complex and compact due to different periods [20]. In contrast, in the Loop irrigation area of the Yellow River, the second largest river in China, new canals and irrigation facilities emerged to replace abandoned fields due to soil salinization [21]. These show the different types of agricultural cultivation in different regions of China.

In Laos, which is also in Asia, the researcher explored the changes in fallow vegetation. The different topographies in which different agricultural types grew in the north were described. As farming vegetation was restored, the slew cycle changed [22]. Similarly, species diversity in agriculture can be represented by Landsat TM images.

3.2.2 Forestry monitoring: Almost a third of the Earth's land surface is covered with forests [23]. Accurate descriptions of forest productivity, biomass, and structure are required to comprehend ecosystem responses to climate and anthropogenic changes. Forests are also fragile and they are susceptible to degradation due to environmental and other impressions. Therefore, it is necessary to study the vegetation in forests with the help of remote sensing techniques. Since it is difficult for people to observe the data of the forest through the field, remote monitoring by remote sensing possesses convenience.

Landsat can provide data when a forest is subjected to fire and deforestation. This is used to study how much the forest can recover on its own when it is disturbed from outside. The results of a study in Canada showed that the type of disturbance determines the trend of recovery after disturbance [24]. This information is critical for understanding the long-term viability of forest management practices, as well as the potential for biomass uptake and carbon sequestration in these Compared to the studies described above, mangrove forests in Bangladesh and India Mangroves, are more vulnerable to tropical cyclones than the studies described above. It takes a catastrophic cyclone, which occurs about once a decade, to have a significant impact [25]. However, according to recent data the frequency of strong cyclones is increasing. Therefore, it needs to be monitored continuously in the future. In observing forests, remote sensing cannot accurately record data for rainforests with closed canopies. This is because such rainforests are sheltered [26]. SAR interferometry is the most likely alternative to such observations.

\subsection{Forecast of disasters}

Disasters are divided into natural and man-made disasters. There have been historical records of natural disasters since ancient times. There is a legend of $\mathrm{Yu} \mathrm{Yu}$ in China, and there are also stories of Noah's Ark refuge in the "Bible" abroad. Since there are records of human civilization, there have been records of natural disasters, indicating that natural disasters coexist with human society, and human society has developed in the struggle against natural disasters. The seriousness of natural disasters is that they not only cause casualties and direct economic losses, but also cause indirect economic losses and social disorder, as well as people's abnormal psychological reactions. With the development of people's economy and society and the increase of population, the area of human living and arable land is getting bigger and bigger. This has caused a lot of damage to the environment, such as serious soil erosion. Assessment of man-made hazards is an effective method of disaster reduction.

3.3.1 Flood monitoring: Floods are one of the most common and costly natural disasters. Therefore, it is necessary to reduce the scale of flooding and reduce the occurrence of loss of life and property. In one study, contemporary SAR time series as well as historical Landsat data on GEE were used to distinguish floods from previously inundated areas [27]. SAR was used in multiple other studies SAR has been shown to have great potential for mapping flooded areas in combination with SAR data and optical remote sensing data in several other studies [28]. SAR imagery has also been applied in an article and their advantage of being unaffected by severe weather is clearly noted [29].

However, sufficient SAR images are not easily available during the coverage flood period and the algorithms for delineating watershed boundaries in SAR images are always time-consuming. Considering open information data platforms like GEE is particularly valuable for operational users to plan emergency response related to floods and to understand flood damage by mapping land cover mapping. In the future techniques such as data fusion of multiple source images are to be considered. In addition, high resolution data with high temporal resolution optical images or SAR data will be combined to improve the accuracy of flood mapping.

\subsubsection{Man-made disaster monitoring: Human} factors have become one of the important factors leading to the occurrence of disaster accidents, and the trend is on the rise. Due to the competent avoidance of manmade disasters, measures can be taken in advance if early detection and research are conducted.

According to studies, the decreasing of the Aral Sea has had a significant influence on the environment, 
livelihoods, economy, and health of the Aral Sea's inhabitants. The Aral Sea is drying due to the massive diversion of source rivers (up to $80 \%$ ) for regional irrigation, which is lost due to increasing evapotranspiration. Ocean runoff and evaporation are slightly influenced by global warming. The drying of the southern brackish waters and the conservation of the northern brackish waters clearly indicate the impact of anthropogenic environmental changes, which may be positive or negative. Given the rising temperatures in the region and the high use of glacial meltwater for irrigation, sustainable water management policies are urgently needed in Central Asia [30].

The research of manmade disasters in China's Luoshan region mentions the tendency of aridification caused by global warming. The population is overburdened, ecological migration programs are being planned, and agriculture is moving from traditional dry farming's decentralized management to highly concentrated agriculture. As a result, land use has grown, resulting in severe water shortages, growing urbanization, human-land tensions, and increased ecological security issues in the region. [31].

\section{CONCLUSION}

Since the invention of sense remoting, its technology has made great contributions to all aspects of human life. Remote sensing satellites can calculate objects on the earth's surface based on their spectra. And with the development of technology, the range of spectra that can be monitored is expanding. This means that more objects can be detected. Earth observation programs based on remote sensing satellites provide the data base for research. The Earth Observation Satellite and Copernicus programs are among the major programs used.

Remote sensing satellites are used for urban planning and development, plant monitoring and disaster prediction. Real-time monitoring and disaster prevention and mitigation are possible. This is where its characteristics of sensitivity and remoteness are applied. The distribution of different objects on the ground can be depicted according to coefficients such as NADI.

\section{ACKNOWLEDGMENT}

This article is completely completed by the author himself, including the writing of the first draft, the processing of the picture information, and the modification and polishing of the format.

\section{REFERENCES}

[1] Z. Shao, W. Wu, and D. Li, "Spatio-temporalspectral observation model for urban remote sensing", Geo-Spatial Information Science. London, vol. 45, pp. 1-15, May 2021.
[2] A. Vaidyanathan, R. P. Dubey, "Proceedings of the national seminar on remoting sensing and agricultural statistics: Rationale, scope and aims," Supportive \& Palliative Care. New York, vol. 3, pp. 61-68, January 2000.

[3] A. Olpenda, K. Stereńczak, and K. Będkowski, "Modeling Solar Radiation in the Forest Using Remote Sensing Data: A Review of Approaches and Opportunities", Remote Sensing. Basel, vol. 10, pp. 694, March 2018.

[4] P. A. Brivio, E. Zilioli, “Assessing wetland changes in the venice lagoon by means of satellite remote sensing data," Journal of Coastal Conservation. Atlanta, vol. 2, pp. 23-32, January 1996.

[5] Y. Sui, H. Guo, G. Liu, and Y. Ren, "Analysis of Long-Term Moon-Based Observation Characteristics for Arctic and Antarctic," Remote Sensing. Basel, vol. 11, p. 2805, April 2019.

[6] T. Aishima, "Chemometrics.Application to Odor Sensing," Journal of the Institute of Electrical Engineers of Japan. Chicago. Washington, vol. 117, pp. 290-293, July 1997.

[7] T. Blaschke, G. T. Hay, and Q. Weng, "Collective Sensing: Integrating Geospatial Technologies to Understand Urban Systems-An Overview," Remote Sensing. Seattle, vol. 3, pp. 1743-1776, May 2011.

[8] C. Xla, A. Xs, and C. Zha, "Improved distortion correction method and applications for large aperture infrared tracking cameras," Infrared Physics \& Technology. Los Angeles, vol. 98, pp. 82-88, November 2019.

[9] A. Lemonsu, V. Viguié, and M. Daniel, "Vulnerability to heat waves: Impact of urban expansion scenarios on urban heat island and heat stress in Paris (France)," Urban Climate. London, vol. 14, pp. 586-605, March 2015.

[10] X. Li, W. Li, and A. Middel, "Remote sensing of the surface urban heat island and land architecture in Phoenix, Arizona: Combined effects of land composition and configuration and cadastraldemographic-economic factors," Remote Sensing of Environment.Silicon Valley, vol. 174, pp. 233 243, Octobor 2016.

[11] P. A. Mirzaei, F. Haghighat "Approaches to study Urban Heat Island - Abilities and limitations," Building and Environment. New York, vol. 45, pp. 2192-2201, Aprial 2010.

[12] M. Santamouris, "Using cool pavements as a mitigation strategy to fight urban heat island-A review of the actual developments," Renewable \& 
Sustainable Energy Reviews. London, vol. 26, pp. 224-240, Janual 2013.

[13] M. Razzaghmanesh, S. Beecham, and T. Salemi, "The role of green roofs in mitigating Urban Heat Island effects in the metropolitan area of Adelaide, South Australia," Urban Forestry \& Urban Greening. New York, vol. 15, pp. 89-102, March 2016.

[14] Y. Hirano, T. Ihara, and K. Gomi, "SimulationBased Evaluation of the Effect of Green Roofs in Office Building Districts on Mitigating the Urban Heat Island Effect and Reducing CO2 Emissions," Sustainability . Basel, vol. 11, p. 2055, May 2019.

[15] F. Kawakubo, R. Morato, and M. Martins, "Quantification and Analysis of Impervious Surface Area in the Metropolitan Region of São Paulo, Brazil," Remote Sensing . Basel, vol. 8, pp.441 Augest 2019.

[16] B. Qiu, H. Li, and C. Chen, "Tracking spatialtemporal landscape changes of impervious surface areas, bare lands, and inundation areas in China during 2001-2017," Land Degradation \& Development. Beijing, vol. 30, London, pp. 18021812, June 2019.

[17] D. Xuegang, M. Zhiguo, and W. Yongzhi, "Monitoring Spatiotemporal Changes of Impervious Surfaces in Beijing City Using Random Forest Algorithm and Textural Features" Remote Sensing. Basel, vol. 13, pp. 153, June 2019.

[18] K. Yang, M. Pan, and Y. Luo, "A time-series analysis of urbanization-induced impervious surface area extent in the Dianchi Lake watershed from 19882017," International Journal of Remote Sensing. Houston, vol. 40, pp. 573-592, April 2021.

[19] J. Beckman, A. M. Countryman, "The Importance of Agriculture in the Economy: Impacts from COVID - 19," American Journal of Agricultural Economics. Washington, vol. 103, pp. 1595-1611, March 2019.

[20] C. Ou, J. Yang, and Z. Du, "Long-Term Mapping of a Greenhouse in a Typical Protected Agricultural Region Using Landsat Imagery and the Google Earth Engine," Remote Sensing (Basel, Switzerland). Seattle, vol. 12, pp. 55, May 2019.

[21] C. Wohlfart, B. Mack, and G. Liu, "Multi-faceted land cover and land use change analyses in the Yellow River Basin based on dense Landsat time series: Exemplary analysis in mining, agriculture, forest, and urban areas," Applied Geography (Sevenoaks), New York, vol. 85, pp. 73-88, March 2017.

[22] C. Liao, Z. Feng, and P. Li, "Monitoring the spatiotemporal dynamics of swidden agriculture and fallow vegetation recovery using Landsat imagery in northern Laos," Journal of Geographical Sciences. Chicago, vol. 25, pp. 1218-1234, Aprial 2015.

[23] C. Xla, A. Xs, and C. Zha, "Improved distortion correction method and applications for large aperture infrared tracking cameras," Infrared Physics \& Technology.Chicago. Berlin, vol. 98, pp. 82-88, February 2019.

[24] J. C. White, M. A. Wulder, and T. Hermosilla, "A nationwide annual characterization of 25 years of forest disturbance and recovery for Canada using Landsat time series," Remote Sensing of Environment. Los Angeles, vol. 194, pp. 303-321, Augest 2017.

[25] M. S. H. Mandal, T. Hosaka, "Assessing cyclone disturbances (1988-2016) in the Sundarbans mangrove forests using Landsat and Google Earth Engine," Natural Hazards (Dordrecht). Sydney, vol. 102, pp. 133-150, May 2020.

[26] H. Astola, T. Häme, and L. Sirro, "Comparison of Sentinel-2 and Landsat 8 imagery for forest variable prediction in boreal region," Remote Sensing of Environment. Cambridge, vol. 223, pp. 257-273, March 2019.

[27] B. DeVries, C. Huang, and J. Armston, "Rapid and robust monitoring of flood events using Sentinel-1 and Landsat data on the Google Earth Engine," Remote Sensing of Environment. New York, vol. 240, p. 111664, Aprial 2020.

[28] X. Zhao, S. H. Li, "Flood Mapping Using ASAR and Landsat Data in Poyang Lake," Applied Mechanics and Materials. Beijing, vol. 145, pp. 114-118, May 2011.

[29] X. Tong, X. Luo, "An approach for flood monitoring by the combined use of Landsat 8 optical imagery and COSMO-SkyMed radar imagery," ISPRS Journal of Photogrammetry and Remote Sensing. Basel, vol. 136, pp. 144-153, Augest 2018.

[30] S. I. Deliry, Z. Y. Avdan, and N. T. Do, "Assessment of human-induced environmental disaster in the Aral Sea using Landsat satellite images," Environmental Earth Sciences. Seoul, vol. 79, pp. 621-632, May 2020.

[31] S. C. Zhu, "The Engineering Management Research Based on Large-scale SPOT5 Images in the Second Investigation of Land-use Change," Remote Sensing Technology \& Application. Beijing, vol. 56, pp. 332-338, May 2006. 